\title{
A comparative study of blood glucose level measurement between glucometer and semi autoanalyser
}

\author{
N.V. Lakshmi' ${ }^{1}$ P. Kiranmai ${ }^{2, *}$ \\ ${ }^{\mathbf{1}}$ Associate Professor, Dept. of Biochemistry, Nizamabad Medical College, (KNR University), Nizamabad, Telangana, ${ }^{\mathbf{2}}$ Associate \\ Professor, Dept. of Biochemistry, Osmania Medical College, (KNR University), Hyderabad, Telangana, India \\ *Corresponding Author: \\ Email: drkiranmai_23@yahoo.co.in
}

Received: $13^{\text {th }}$ April, 2018

Accepted: $17^{\text {th }}$ April, 2018

\begin{abstract}
Introduction: There is a direct relationship between glycemic control and risk of systemic complications leading to high morbidity and mortality in diabetes. ${ }^{3}$ Estimation of blood glucose is the main investigation for the diagnosis and management of diabetes mellitus and also for monitoring emergency complications of DM. Glucometers are used for monitoring blood glucose levels in most of the hospitals. There is a need for establishing the reliability of results of glucometer as they also have limitations. ${ }^{6}$ Our study is undertaken to compare the glucose levels in capillary whole blood by glucometer and glucose levels in venous plasma samples by semi autoanalyser.

Materials and Methods: Study was conducted in the department of Biochemistry Osmania General Hospital. 50 Subjects both male and female in the age group of 25 to $65 \mathrm{yrs}$ attending out patient department of Medicine at Osmania General Hospital were included in the study. Capillary blood glucose is measured with a glucometer and venous plasma sample glucose is measured with a semi autoanalyser. Statistical analysis is done by mean comparison and student $t$ test.

Results: When the two means are compared there is increase in the blood glucose levels measured by using a glucometer (117.76 \pm 39.01$)$ when compared to venous blood samples levels measured by using a semi autoanalyzer $(108.78 \pm 39.05)$ but there is no statistical significance $(\mathrm{P}>0.05)$. Results showed a variation of $2 \%$ to $15 \%$ in individual subjects between the blood glucose levels by two methods.

Conclusion: Mean glucose levels in capillary blood sample estimated by glucometer is higher than the mean glucose levels in venous plasma samples estimated by semi autoanalyser, but there is no statistical significance. Hence glucometer can be used at bedside as a better alternative for out patient department diagnosis and in emergency situations.
\end{abstract}

Keywords: Glucometer, Semi auto analyser, Blood glucose.

\section{Introduction}

Diabetes Mellitus (DM) is the most common metabolic disorder in the world. In western population the prevalence is $5-10 \% .{ }^{1}$ In developing countries like India, its prevalence is increasing rapidly. According to international diabetes federation 61.3 million people had diabetes in 2011, by 2030 it will rise to 101.2 million. $^{2}$

There is a direct relationship between glycemic control and risk of systemic complications leading to high morbidity and mortality in diabetes. ${ }^{3}$ Estimation of blood glucose is the main investigation for the diagnosis and management of diabetes mellitus and also for monitoring emergency complications of DM like diabetic ketoacidosis, hypoglycemia and nonketotic hyperosmolar hyperglycemia.

In most of the hospitals, out patient clinics, emergency rooms and home self monitoring blood glucose levels glucometers are used for monitoring blood glucose levels. ${ }^{4,5}$ Glucometer monitoring is more easier, convenient, quicker and cheap method. So there is a need for establishing the reliability of results of Glucometer as they also have limitations. ${ }^{6}$ It is challenging to establish the accuracy of blood glucose level obtained from the glucometer which measures capillary blood sample and not venous sample.
American Diabetes Association (ADA) guidelines for diagnosis of DM refers to venous sample. ${ }^{7}$

Our study is undertaken to compare the glucose levels in capillary whole blood by glucometer and glucose levels in venous plasma samples by semi autoanalyser in all patients attending the out patient clinics irrespective of their diabetic and non diabetic status and to establish the accuracy of glucometer blood glucose estimation compared to laboratory Semi auto analyser.

\section{Materials and Methods}

Study was conducted in the department of Biochemistry Osmania General Hospital. 50 Subjects both male and female in the age group of 25 to $65 \mathrm{yrs}$ attending out patient department of Medicine at Osmania General Hospital were included in the study. All the patients who were advised for blood glucose estimation were selected and asked to come the next day in $8 \mathrm{hrs}$ fasting state. Subjects were selected irrespective of their diabetic status. After due consent taken from the subjects fasting venous sample of $3 \mathrm{ml}$ is collected and samples are sent to the biochemistry lab. Plasma glucose is estimated in the samples by Glucose Oxidase Peroxidase (GOD-POD) method by using a Semi autoanalyser. (Transasia) ${ }^{8,9}$ At the same time in all the subjects blood 
glucose estimation was done by glucometer (Accucheck) in capillary sample collected by finger prick method. ${ }^{10}$

\section{Statistical Analysis}

The results were analysed on SSPS statistical software. All estimates were presented as Mean + SD and statistical treatment were performed using student $t$ test. $P$ value $\leq 0.05$ were considered as statistically significant.

\section{Results}

Study group includes 50 subjects in the age group of 25 to 65 yrs. Venous plasma blood glucose is measured in all the 50 subjects by using semi autoanalyzer and capillary blood glucose is measured in the same subjects at the same time by using glucometer.

The results are recorded in a master chart (Table 1). Blood sugar levels by two methods in each subject are compared and percent difference between the two values are compared (Table 1). Results showed a variation of $2 \%$ to $15 \%$ in individual subjects between the blood glucose levels by two methods.

Table 1: Comparison of glucose levels estimated by glucometer and semi autoanalyser

\begin{tabular}{|c|c|c|c|c|c|}
\hline S. No & Age & Sex & $\begin{array}{l}\text { Glucose Measured with } \\
\text { Glucometer (mg/dl) }\end{array}$ & $\begin{array}{c}\text { Glucose Measured with Semi } \\
\text { Autoanalyser (mg/dl) }\end{array}$ & \% Difference \\
\hline 1 & 32 & $\mathrm{M}$ & 104 & 90 & 15 \\
\hline 2 & 68 & $\mathrm{M}$ & 120 & 117 & 2.5 \\
\hline 3 & 40 & $\mathrm{M}$ & 101 & 92 & 9.7 \\
\hline 4 & 60 & $\mathrm{~F}$ & 86 & 70 & 13 \\
\hline 5 & 40 & $\mathrm{~F}$ & 112 & 100 & 12 \\
\hline 6 & 25 & $\mathrm{~F}$ & 95 & 84 & 13 \\
\hline 7 & 33 & $\mathrm{M}$ & 162 & 144 & 12.5 \\
\hline 8 & 65 & $\mathrm{M}$ & 82 & 76 & 7.8 \\
\hline 9 & 60 & $\mathrm{M}$ & 116 & 104 & 11.5 \\
\hline 10 & 45 & $F$ & 93 & 80 & 8.7 \\
\hline 11 & 32 & $\mathrm{~F}$ & 204 & 200 & 2 \\
\hline 12 & 45 & $F$ & 82 & 80 & 2.5 \\
\hline 13 & 52 & $\mathrm{M}$ & 104 & 100 & 4 \\
\hline 14 & 39 & $\mathrm{M}$ & 101 & 88 & 14.7 \\
\hline 15 & 50 & $F$ & 84 & 76 & 10.5 \\
\hline 16 & 23 & $\mathrm{~F}$ & 100 & 92 & 8.6 \\
\hline 17 & 55 & $\mathrm{M}$ & 100 & 88 & 13. \\
\hline 18 & 42 & $\bar{F}$ & 180 & 180 & 0 \\
\hline 19 & 25 & $\mathrm{~F}$ & 185 & 184 & 0 \\
\hline 20 & 28 & $\mathrm{M}$ & 127 & 122 & 4 \\
\hline 21 & 38 & $\mathrm{~F}$ & 170 & 150 & 13.3 \\
\hline 22 & 25 & $\mathrm{~F}$ & 107 & 104 & 2.8 \\
\hline 23 & 42 & $\mathrm{~F}$ & 109 & 100 & 9 \\
\hline 25 & 28 & $\mathrm{M}$ & 93 & 88 & 5.6 \\
\hline 26 & 45 & $\mathrm{M}$ & 82 & 76 & 7.8 \\
\hline 27 & 60 & $\mathrm{M}$ & 89 & 79 & 12.6 \\
\hline 28 & 39 & $\mathrm{~F}$ & 184 & 166 & 10.8 \\
\hline 29 & 50 & $\mathrm{~F}$ & 105 & 95 & 10.5 \\
\hline 30 & 50 & $\mathrm{M}$ & 95 & 86 & 10.4 \\
\hline 31 & 56 & $\mathrm{M}$ & 79 & 70 & 12.8 \\
\hline 32 & 45 & $\mathrm{M}$ & 100 & 87 & 13 \\
\hline 33 & 50 & $\mathrm{~F}$ & 104 & 93 & 11.8 \\
\hline 34 & 65 & $\mathrm{M}$ & 224 & 211 & 6.16 \\
\hline 35 & 50 & $\mathrm{~F}$ & 104 & 91 & 14.2 \\
\hline 36 & 38 & $\mathrm{~F}$ & 90 & 84 & 7.1 \\
\hline 37 & 35 & $\mathrm{M}$ & 240 & 225 & 6.6 \\
\hline 38 & 60 & $\mathrm{M}$ & 112 & 100 & 13.04 \\
\hline 39 & 65 & $\mathrm{M}$ & 96 & 86 & 11.6 \\
\hline 40 & 64 & $\mathrm{M}$ & 100 & 88 & 13.63 \\
\hline 41 & 55 & $\mathrm{M}$ & 101 & 101 & 0 \\
\hline
\end{tabular}




\begin{tabular}{|l|c|c|c|c|c|}
\hline 42 & 34 & $\mathrm{M}$ & 125 & 116 & 7.75 \\
\hline 43 & 65 & $\mathrm{M}$ & 87 & 78 & 11.53 \\
\hline 44 & 38 & $\mathrm{M}$ & 114 & 103 & 10.67 \\
\hline 45 & 54 & $\mathrm{M}$ & 98 & 90 & 8.88 \\
\hline 46 & 40 & $\mathrm{M}$ & 198 & 192 & 3.12 \\
\hline 47 & 55 & $\mathrm{~F}$ & 156 & 149 & 4.69 \\
\hline 48 & 55 & $\mathrm{M}$ & 102 & 99 & 3.03 \\
\hline 49 & 58 & $\mathrm{M}$ & 88 & 87 & 1.14 \\
\hline 50 & 66 & $\mathrm{M}$ & 90 & 79 & 13.92 \\
\hline
\end{tabular}

The mean plasma venous blood glucose measured by Semi autoanalyzer is $108.78 \pm 39.05$ and mean capillary blood glucose measured by glucometer is $117.76 \pm 39.01$. When the two means are compared there is increase in the blood glucose levels measured by using a glucometer when compared to venous blood samples levels measured by using a semi autoanalyzer but there is no statistical significance $(\mathrm{P}>0.05)$ (Table 2) Fig. 1.

Table 2: Comparison of mean glucose levels measured by two methods

\begin{tabular}{|l|l|l|c|c|}
\hline \multicolumn{1}{|c|}{ Method } & Sample & Mean blood Glucose & t value & P value \\
\hline Glucometer & Capillary blood & $117.76+39.01$ & 1.13 & $0.129(>0.05)$ \\
\cline { 1 - 2 } Semi Autoanalyser & Venous Plasma & $108.78+39.05$ & & NS \\
\hline
\end{tabular}

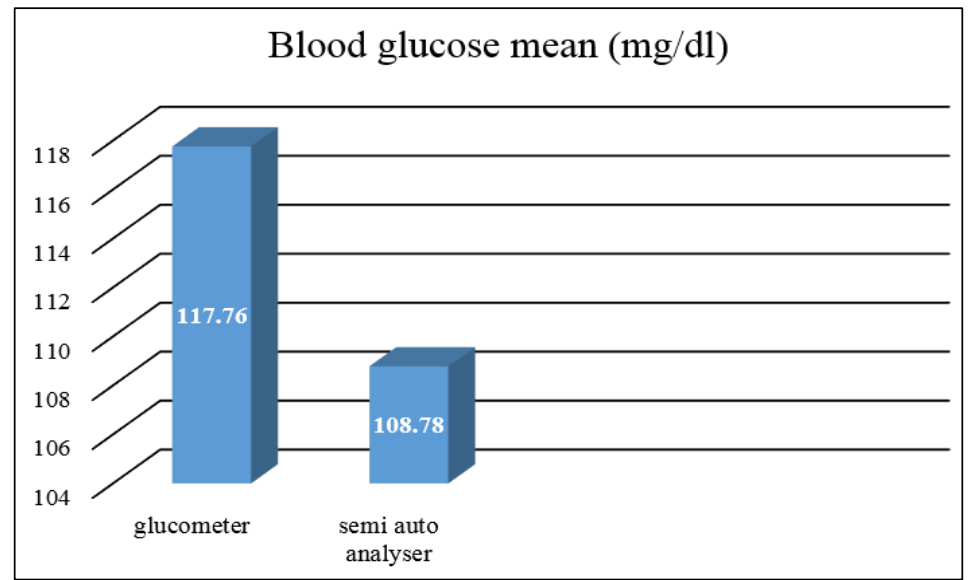

Fig. 1: Comparison of mean blood glucose levels estimated by glucometer and semi autoanalyser

\section{Discussion}

In our study the mean blood glucose estimated by glucometer is higher than mean venous plasma glucose estimation by Semi autoanalyzer but there is no statistical significance. Similar outcome was observed in other studies also. ${ }^{11,12}$ Capillary blood glucose is camparable to arterial blood glucose level. Literature indicates a difference of $7 \%$ between postprandial arterial blood glucose and post prandial venous blood glucose with venous blood glucose being lower. But not significant difference in fasting samples. This is explained by absorption of glucose by the tissue cells via diffusion in peripheral capillaries and some glucose returns to veins. ${ }^{13}$ So venous plasma glucose level is the estimate glucose after utilization of glucose by tissues, which inturn is dependant on effects of insulin, glucagon, cortisol, postprandial and preprandial status. This explains the lower levels of glucose in venous blood samples in our study when compared to capillary blood glucose levels measured with a glucometer. Statistical significance is not seen as the samples analysed are fasting samples.

Previous studies regarding the accuracy of blood glucose estimate when comparing glucometer against semi autoanalyser methods are giving different opinions. ${ }^{6,14-16}$ American Diabetes Association has recommended that glucometers agree to within $+15 \%$ of the lab method at all concentrations. ${ }^{4}$ In our study the difference in the glucose levels for each subject varied between 2 to $15 \%$ which is well within the recommendation of ADA.

Studies indicate an error of measurement of blood glucose using glucometer by hemodynamic factors like edema, use of vasopressor agents, use of insulin. Fluctuations occur with changes in temperature and humidity. ${ }^{16}$ The transport of venous blood sample collected in rural areas or at home is problematic. Accuracy in analysis may be affected if venous blood is not transported and processed in a timely fashion.

In our study though a variation is observed between the blood glucose levels measured by glucometer and 
semi autoanalyser there is no statistical significance. Individual subject variation of blood glucose levels showed only a difference of 2 to $15 \%$. So capillary blood glucose measurement using glucometer a portable point of care device is a recommendable alternative to venous plasma glucose sample estimation using a semi auto analyser as it is convenient, easier, and less invasive technique. ${ }^{5,15}$

\section{Conclusion}

Mean glucose levels in capillary blood sample estimated by glucometer is higher than the mean glucose levels in venous plasma samples estimated by semi autoanalyser, but there is no statistical significance. The difference between the two values measured by the two methods in each subject ranged between $2 \%$ to $15 \%$. Hence glucometer can be used at bedside as a better alternative for out patient department diagnosis and in emergency situations. Capillary blood glucose done on glucometer is acceptable but it should be confirmed by venous plasma glucose levels for diagnosis and monitoring of diabetes mellitus.

\section{References}

1. Longo, Casper, Fauci. Hauser, Jameson, Loscalzo, Harrison principles of Medicine. Diabetes Mellitus. 18th ed. Mc grow Hill 2011;(2), 2969-70.

2. Dr. Anu Gaikwad, Dr. Shubhangi Kanitkar, Dr. Meenakshi Kalyan, Dr. Krunal Tamakuwala, Dr Rajani Agarwal, Dr. Bhargav Bhim avarapu, Prevalence of type 2 diabetes mellitus in candidates contesting for municipal corporation elections in an urban industrialized town, Indian Journal of Basic and Applied Medical Research; March 2014:Vol.-3, Issue- 2, P.412-418.

3. Arend, Armitage, Clemmons, Drazen, Griggs, Landry, Levison, Rustgi, Scheld Goldman's Cecil Medicine 2nd edition, Chapter 237, 1491.

4. Chen ET, Nichols JH, Duh SH, Hortin G. Performance evaluation of blood glucose monitoring devices. Diabetes Technol Ther. 5(5), 2003, 749-68.

5. Blake DR, Nathan DM. Point-of-care testing for diabetes. Crit Care Nurs Q. 27(2), 2004, 150-61.
6. Tonyushkina K, Nichols JH. Glucose Meters: A Review of Technical Challenges to Obtaining Accurate Results. $J$ Diabetes Sci Technol. 2009 Jul 1;3(4):971-80.

7. Longo, Casper, Fauci. Hauser, Jameson, Loscalzo, Harrison principles of Medicine. Diabetes Mellitus. 18th ed. Mcgrow Hill 2011;(2), 2970-71. 4.

8. Trinder. P Ann. clin. Biochem 19696.24

9. Emerson Lorg. chem. 1943.8.417

10. American Diabetes association, Standard of Medical Care in Diabetes Jan 2006; vol.29 no. (suppl. 1):s4-s42.

11. Biag A, Saddiqui 1, Jabbar A, Azam SI, Sabir S, Alam S, Ghani F. Comparison between bedside testing of blood glucose by glucometer vs centralized testing in a tertiary care hospital. J Ayub Med Coll Abbottabad. 2007 JulSep;19(3):25-9. Available form: http://www.ncbi.nih.gov/pubmed/18444586.

12. Colagiuri S, Sandbak A, Carstensen B, Christiansen J. et al. Comparibility of venous and capillary glucose measurements in blood. Diabet Med. 2003 Nov; 20(11):953-6. Available form: http://www. ncbi.nih.gov/pubmed/14632723.

13. Risaiah B., Self monitering of blood glucose level: potential sources of inaccuracy. Can Med Assoc J. 1985 Jun 15;132(12):1357-1359,1361. PMCID: PMC1346098

14. R. Tirimaccoa, P. Tideman, c, J. A. Dunbar, E. Janus. Should capillary blood glucose measurements be used in population surveys? International Journal of Diabetes Mellitus. Published by Elsevier Ltd. 1877-5934 2009 doi:10.1016/j.ijdm.2009.12.002.

15. Dr. Subha Palaneeswari. M, Dr. K. Sumathi1 and Dr. A.J. Manjula Devi, Glucose Meter - A Boon To The 21st Century, Int J Pharm Bio Sci 2013 4(4), oct, (b) 553-558.

16. Haller MJ, Shuster JJ, Schatz D, Melker RJ. Adverse impact of temperature and humidity on blood glucose monitoring reliability: a pilot study. Diabetes Technol Ther. 9(1), 2007, 1-9.

How to cite this article: Lakshmi NV, Kiranmai P. A comparative study of blood glucose level measurement between glucometer and semi autoanalyser. Int $\mathrm{J}$ Clin Biochem Res. 2018;5(3):423-426. 